\title{
The experimental neuropathy in rats caused by p-bromophenylacetylurea
}

\author{
J. B. CAVANAGH, F. C. K. CHEN, M. H. KYU, AND A. RIDLEY \\ From the M. R. C. Research Group in Applied Neurobiology, \\ Institute of Neurology, Queen Square, London
}

In 1960, Diezel and Quadbeck reported that parabromophenylacetylurea, when given to rats by mouth in a single dose of $200 \mathrm{mg} / \mathrm{kg}$, caused paralysis of the hind limbs after an interval of 10-14 days. Of 12 halogenated derivatives of phenylacetylurea that these authors studied only this compound had this effect. When they examined these animals histologically up to one month after poisoning, they found degeneration of peripheral nerve fibres and changes in the anterior horn cells and in the white matter of the spinal cord. In view of the apparent similarity of the distribution of the paresis and of the length of the delay period before the onset of symptoms to the neurotoxic sequelae of certain organophosphorus compounds (Cavanagh, $1964 a, b)$, the toxic effects of this substance have been examined in more detail.

\section{MATERIALS AND METHODS}

Para-bromophenylacetylurea, a white crystalline powder, was kindly synthesized for us by Dr. A. R. Mattocks of the M.R.C. Toxicology Research Unit, Carshalton. Because of its low solubility in aqueous and most organic solvents, it was dissolved in dimethyl sulphoxide (DMSO)- (except in one experiment where emulsification in a $20 \%$ aqueous solution of Tween 80 (polyoxyethylene sorbitan mono-oleate) was used-and given by mouth through a polyethylene cannula under light ether anaesthesia on two successive days.

Albino rats, male and female, of Porton strain were used. They were housed in plastic boxes and fed Chardex ad libitum.

The animals were weighed and examined daily. They were observed for motor weakness and inco-ordination either during normal movements or when put through a series of tests. These included ability to right themselves and land after falling from a height of $2-3 \mathrm{ft}$, ability to find and grasp a sloping wire with fore and hind limbs, ability to climb onto a smooth metal bar, and ability to haul themselves onto a raised metal cage top by their fore limbs. On the basis of their capacity to perform these tests of strength and co-ordination their functional disability was placed on a five-point scale, thus: (1.0) suspicion of functional disability and inco-ordination; (2.0) definite weakness and/or inco-ordination of hind limbs, particularly the feet; (3.0) marked weakness of hind limbs, especially the feet, loss of splay reflex, hypotonia, and progression by 'paddling' with the proximal parts of the limbs; (4.0) weakness now including the proximal parts of the hind limbs and slight weakness of fore limbs; (5.0) marked weakness of fore limbs in addition to severe hind limb involvement. Assessment on this basis was employed in order to reduce the subjective element as far as possible in making comparisons between groups of animals.

PREPARATION OF TISSUES At various times after poisoning, the animals were deeply anaesthetized with chloroform, pinned out onto a cork board, and a cannula was rapidly passed into the ascending aorta through the left ventricle. After a brief $(30 \mathrm{sec})$ flow of saline, formol-acetic acid $(10 \% 1 \% \mathrm{~V} / \mathrm{V})$ was run in under a pressure of $80 \mathrm{~cm}$ of water. The perfusion was continued for $15-30 \mathrm{~min}$, after which the brain case was opened, and the spinal column and other tissues were cut out for a further 24-hr fixation. The sciatic nerve was laid onto a card in a lightly stretched position, and allowed to adhere before fixation. Saphenous and posterior tibial nerves were excised at the onset of perfusion, laid onto pieces of card, and fixed in Flemming's fluid for fibre diameter measurements.

Blocks of cerebrum, brain-stem and cerebellum, medulla, cervical, thoracic and lumbar cord, cervical, lumbar and trigeminal ganglia, and sciatic nerves were embedded in paraffin, cut at $10 \mu$ and stained with haematoxylin and eosin, cresyl fast violet, and Glees and Marsland's silver stain for axons. Blocks of muscle from foot, anterior tibial region, quadriceps femoris, and psoas muscle were embedded in gelatine and sectioned at $30 \mu$. These were stained with sudan black B and Schofield's silver method for nerve fibres. A few peripheral nerves were stained with oil red $O$ after teasing to determine if any significant amount of segmental demyelination were present. The Marchi method was used on a few selected spinal cords.

Fibre diameters were measured directly from transverse sections with an oil immersion $(\times 100)$ objective and a moveable ocular graticule. This is quicker and more accurate than the photographic methods, and, if the nerve is systematically covered, only minimal overor under-counting occurs. 


\section{RESULTS}

FUNCTIONAL RESPONSES (Table I) After a dose on two consecutive days of $200 \mathrm{mg} / \mathrm{kg}$ in dimethylsulphoxide (DMSO), no serious functional disturbances occurred other than a slight drop in weight of 5 to $20 \mathrm{~g}$, which was made up by the third or fourth day. This followed the use of Tween 80 as a vehicle as well as DMSO and occurred equally at all doses used. The animals' weight, thereafter, continued to increase in the normal manner until paresis ensued.

When the vehicle was DMSO paresis became detectable from the seventh day with $2 \times 400 \mathrm{mg} / \mathrm{kg}$, and on subsequent days with decreasing doses. Weakness and clumsiness of the hind paws and apparent loss of awareness of their position in space were the earliest signs, coupled with hypotonia or floppiness of the hind limb movements. The splay reflex also disappeared. Over the next five to seven days the disability spread to affect the more proximal parts of the limb and the paws became progressively more immobile and flaccid. At 3.0 degrees of disability, the animal was propelled partly by 'paddling' movements of its hind limbs, but mostly by fore-limb activity. At 4.0 and 5.0 degrees of disability there was also increasing weakness and flaccidity of the fore limbs. In addition diarrhoea, urinary incontinence, chromodacryorrhoea, harsh 'squawking' sounds, and hyperpnoea occurred in several animals after the 15-17th day when paresis was maximal. In a few animals haematuria was also observed.

In Tween 80 the effects of $2 \times 200 \mathrm{mg} / \mathrm{kg}$ were similar to those of $2 \times 200 \mathrm{mg} / \mathrm{kg}$ in DMSO, while smaller doses had considerably less effect than their $\frac{\text { O }}{Z}$ equivalents in DMSO.

In summary, after a constant delay period the paresis begins distally in the hind limbs and spreads proximally over this period, and in more severelyô affected animals the fore limbs becomes affected ${ }_{0}$ later on. Whether sensation is similarly affected could not be ascertained with confidence.

EFFECTS OF AGE ON TOXICITY (Table I) Three weanling (3-week old) rats were dosed orally with $2 \times 200 \mathrm{~s}$ $\mathrm{mg} / \mathrm{kg}$ in DMSO. The delay period was lengthened 0 and the degree of disability was significantly less 들 than in adult rats. All three rats (two females, one $\frac{\bar{s}}{\sigma}$ male) were equally affected. The degree of disability $\Phi$ was equivalent to that after $2 \times 100 \mathrm{mg} / \mathrm{kg}$ in the adults, but recovery was quicker.

RESPONSE OF OTHER SPECIES One adult rabbit $\overrightarrow{\vec{\omega}}$ (Copenhagen White) and one guinea-pig of mixed $\stackrel{\omega}{\sigma}$ stock were given $2 \times 200 \mathrm{mg} / \mathrm{kg}$ by mouth in DMSO. Neither showed any weight loss or func- $\frac{7}{0}$ tional disability. No histological changes were found $\underline{\omega}$ in the spinal cord examined one month after ir poisoning.

One adult chicken (Rhode Island Red X Lighit Sussex) was given $200 \mathrm{mg} / \mathrm{kg}$ orally by Dr. J. N Barnes at the M.R.C. Toxicology Research Unie Carshalton. Since no signs developed, this was $O$ repeated on the 10th, 17th, 50th, 51st, and 52ng days without functional result (personal con munication).

EFFECT OF SEX ON THE PARALYTIC RESPONSE Of fOU adult female rats studied, three developed 3 degrees

TABLE I

RESPONSE TO DIFFERENT ORAL DOSES OF P-BROMOPHENYLACETYLUREA

\begin{tabular}{|c|c|c|c|c|c|c|c|c|c|c|c|c|c|c|c|c|c|c|}
\hline \multirow{2}{*}{ Oral dose $(\mathrm{mg} / \mathrm{kg})$} & \multirow[t]{2}{*}{ Animals (no.) } & \multirow{2}{*}{$\operatorname{Sex}$} & \multicolumn{16}{|c|}{ Days after dosing } \\
\hline & & & 6 & 7 & 8 & 9 & 10 & 11 & 12 & 13 & 14 & 15 & 16 & 17 & 18 & 19 & 20 & 21 \\
\hline $\begin{array}{l}2 \times 400 \\
\text { in DMSO }\end{array}$ & $\stackrel{2}{\text { (adult) }}$ & $\mathbf{M}$ & $\mathbf{0}$ & $1 \cdot 0$ & $1 \cdot 5$ & $2 \cdot 0$ & $3 \cdot 0$ & $3 \cdot 5$ & $4 \cdot 0$ & $4 \cdot 5$ & $4 \cdot 5$ & $4 \cdot 5$ & $4 \cdot 5$ & $4 \cdot 5$ & $4 \cdot 5$ & $4 \cdot 5$ & $5 \cdot 0$ & $5 \cdot 0$ \\
\hline $\begin{array}{l}2 \times 200 \\
\text { in DMSO }\end{array}$ & $\begin{array}{c}12 \\
\text { (adult) }\end{array}$ & $\begin{array}{l}4 \mathrm{~F} \\
8 \mathrm{M}\end{array}$ & $\mathbf{0}$ & $0 \cdot 1$ & $1 \cdot 1$ & $1 \cdot 5$ & $2 \cdot 2$ & $3 \cdot 0$ & $3 \cdot 5$ & $3 \cdot 5$ & $3 \cdot 5$ & $4 \cdot 0$ & $4 \cdot 0$ & $4 \cdot 0$ & $4 \cdot 0$ & $4 \cdot 0$ & $4 \cdot 0$ & 4.0 \\
\hline $\begin{array}{l}2 \times 100 \\
\text { in DMSO }\end{array}$ & $\begin{array}{c}2 \\
\text { (adult) }\end{array}$ & $\mathbf{M}$ & $\mathbf{0}$ & $\mathbf{0}$ & $\mathbf{0}$ & 0.75 & $2 \cdot 0$ & $2 \cdot 5$ & $3 \cdot 0$ & $3 \cdot 5$ & $4 \cdot 0$ & $4 \cdot 0$ & 3.5 & $4 \cdot 0$ & $4 \cdot 0$ & $3 \cdot 5$ & $3 \cdot 5$ & $4 \cdot 0$ \\
\hline $\begin{array}{l}2 \times 50 \\
\text { in DMSO }\end{array}$ & $\begin{array}{c}2 \\
\text { (adult) }\end{array}$ & $\mathbf{M}$ & 0 & $\mathbf{0}$ & 0 & 0.5 & $1 \cdot 0$ & $1 \cdot 0$ & $2 \cdot 0$ & $3 \cdot 0$ & $3 \cdot 5$ & $3 \cdot 0$ & 3.0 & $3 \cdot 0$ & $3 \cdot 0$ & 3.5 & 3.5 & $3 \cdot 5$ \\
\hline $\begin{array}{l}2 \times 200 \\
\text { in DMSO }\end{array}$ & $\begin{array}{c}3 \\
\text { (weanling) }\end{array}$ & $\begin{array}{l}\mathbf{1 M} \\
\mathbf{2 F}\end{array}$ & 0 & 0 & 0 & 0 & 1.0 & $2 \cdot 0$ & $2 \cdot 0$ & $2 \cdot 0$ & 3.0 & 3.0 & $3 \cdot 0$ & $3 \cdot 0$ & 3.0 & $2 \cdot 0$ & $2 \cdot 0$ & $2 \cdot 0$ \\
\hline None* & $\begin{array}{c}2 \\
\text { (adult) }\end{array}$ & $\mathbf{M}$ & 0 & 0 & 0 & 0.5 & 0.5 & 0.5 & $\mathbf{0}$ & $\mathbf{0}$ & 0.5 & $1 \cdot 0$ & $1 \cdot 0$ & 1.0 & 1.0 & $0 \cdot 1$ & $1 \cdot 0$ & $1 \cdot 0$ \\
\hline Nonet & $\begin{array}{c}2 \\
\text { (adult) }\end{array}$ & $\mathbf{M}$ & $\mathbf{0}$ & 0 & 0 & 0 & 0 & $\mathbf{0}$ & $\mathbf{0}$ & 0 & 0 & $\mathbf{0}$ & 0 & 0 & 0.5 & 0 & 0 & 0 \\
\hline
\end{tabular}

*In same cage as rats given $2 \times \mathbf{4 0 0} \mathrm{mg} / \mathbf{k g}$ in DMSO

† In same cage as rats given $2 \times 200 \mathrm{mg} / \mathrm{kg}$ in DMSO

DMSO = Dimethyl sulphoxide

Figures are mean degrees of disability expressed on a five-point scale 
of paresis and only one 4 degrees, whereas all of the eight adult male rats developed 4 degrees of paresis on the same dose. This finding suggested that adult females may be slightly less susceptible than males, but has not been studied further. Of the three weanling rats studied (two females, one male), no sex difference was apparent.

EFFECTS OF RATS MAINTAINED ON A SUBNEUROTOXIC DAILY INTAKE OF ISONIAZID (ISONICOTINIC ACID HYDRAZIDE) (Table II) Five adult male rats were given a diet (Chardex) containing $0.25 \%$ isoniazid providing a daily intake of $160 \mathrm{mg} / \mathrm{kg}$, calculated on the amount of diet consumed. This dose of isoniazid will stop the normal daily weight increase and will produce a degree of peripheral-mainly motornerve damage that can be demonstrated histologically, but produced no detectable disturbance in locomotor activity within four weeks (Cavanagh, 1967).

After one week on INH they were given $2 \times 200$ $\mathrm{mg} / \mathrm{kg}$ p-bromophenylacetylurea by mouth. The earliest signs of disability began six days later, and the animals became severely paralysed (5 degrees) by the 15th-16th day. The delay period was thus slightly shortened and the degree of paresis enhanced by this procedure.

TRANSFER OF TOXIC MATERIAL TO RATS KEPT IN THE SAME CAGE (Tables I and II) Two adult male rats were given $2 \times 400 \mathrm{mg} / \mathrm{kg}$ and two given $2 \times 200$ $\mathrm{mg} / \mathrm{kg}$ p-bromophenylacetylurea. Each pair was housed in the same cage as a pair of normal adult male rats matched for weight. The undosed rats housed with those given $2 \times 400 \mathrm{mg} / \mathrm{kg}$ showed a flattening of their weight curves that paralleled the similar flattening of the weight curves of the dosed rats. One of these two developed 1.0 degree of paresis that persisted over the next two weeks. The other, and those housed with the $200 \mathrm{mg} / \mathrm{kg}$ animals, remained normal (Table I). When these rats housed with $400 \mathrm{mg} / \mathrm{kg}$ animals were killed 28 days after poisoning, both non-dosed animals showed moderate degenerative changes in the spinal cords.

The experiment was repeated on two occasions with animals maintained on INH (0.25\%) in the diet. After one week, half the animals were given $2 \times 200 \mathrm{mg} / \mathrm{kg}$ p-bromophenylacetylurea by mouth. In the first experiment all three undosed animals developed definite paresis, while in the second experiment, one of two animals became paralysed (Table II). The signs developed rather more slowly and the effects were less severe in the undosed than in the dosed animals.

Toxic material would thus seem to have been transferred from dosed to undosed animals in amounts sufficient to cause paralysis. Those housed with animals given $2 \times 400 \mathrm{mg} / \mathrm{kg}$ developed paralysis of a degree found otherwise with $2 \times 50$ $\mathrm{mg} / \mathrm{kg}$ in DMSO, so that a substantial amount of material must, therefore, have been transferred. INH in the diet enhanced this phenomenon.

STRUCTURAL CHANGES These were studied in animals given $2 \times 200 \mathrm{mg} / \mathrm{kg}$ by killing and fixing the tissues at various times from five days to six weeks after the first dose.

\section{TABLE II}

EFFECT OF EMULSIFICATION WITH TWEEN 80 AND OF ISONIAZID (160 MG/KG/DAY) ON NEUROTOXICITY OF P-BROMOPHENYLACETYLUREA. TRANSFER OF TOXICITY TO ANIMALS KEPT IN SAME CAGE

\begin{tabular}{|c|c|c|c|c|c|c|c|c|c|c|c|c|c|c|c|c|c|c|}
\hline Oral dose $(\mathrm{mg} / \mathrm{kg})$ & Animals (no.) & $\operatorname{Sex}$ & 6 & 7 & 8 & 9 & 10 & 11 & 12 & 13 & 14 & 15 & 16 & 17 & 18 & 19 & 20 & 21 \\
\hline \multicolumn{19}{|l|}{ Normal diet } \\
\hline $\begin{array}{l}2 \times 200 \\
\text { in DMSO }\end{array}$ & $\begin{array}{c}12 \\
\text { (adult) }\end{array}$ & $\begin{array}{l}4 F \\
8 M\end{array}$ & 0 & $0 \cdot 1$ & $1 \cdot 1$ & $1 \cdot 5$ & $2 \cdot 2$ & $3 \cdot 0$ & $3 \cdot 5$ & $3 \cdot 6$ & $3 \cdot 6$ & $3 \cdot 8$ & $3 \cdot 8$ & $3 \cdot 8$ & $3 \cdot 8$ & $3 \cdot 8$ & 3.8 & 3.8 \\
\hline $\begin{array}{l}2 \times 200 \\
\text { in } T \text { ween } 80\end{array}$ & $\begin{array}{c}2 \\
\text { (adult) }\end{array}$ & $\mathbf{M}$ & $\mathbf{0}$ & $\mathbf{0}$ & 1.0 & $1 \cdot 0$ & $2 \cdot 0$ & 3.0 & 3.5 & $3 \cdot 5$ & $3 \cdot 5$ & $4 \cdot 0$ & $4 \cdot 2$ & $4 \cdot 2$ & $4 \cdot 0$ & $4 \cdot 0$ & $4 \cdot 0$ & $4 \cdot 0$ \\
\hline $\begin{array}{l}2 \times 100 \\
\text { in Tween } 80\end{array}$ & $\begin{array}{c}2 \\
\text { (adult) }\end{array}$ & $\mathbf{M}$ & 0 & 0 & 0 & $\mathbf{0}$ & 0 & 0 & 0.5 & 0.5 & $1 \cdot 0$ & $1 \cdot 0$ & $1 \cdot 0$ & 1.5 & $1 \cdot 5$ & $1 \cdot 5$ & $1 \cdot 5$ & $2 \cdot 0$ \\
\hline $\begin{array}{l}2 \times 50 \\
\text { in } \mathrm{T} \text { ween } 80\end{array}$ & $\begin{array}{c}2 \\
\text { (adult) }\end{array}$ & $\mathbf{M}$ & $\mathbf{0}$ & 0 & 0 & 0 & $\mathbf{0}$ & $\mathbf{0}$ & $\mathbf{0}$ & $\mathbf{0}$ & $\mathbf{0}$ & $\mathbf{0}$ & 0.5 & $\mathbf{0}$ & 0.5 & $\mathbf{0}$ & 0.5 & 0.5 \\
\hline \multicolumn{19}{|l|}{ INH diet $1 / 52$} \\
\hline $\begin{array}{l}2 \times 200 \\
\text { in DMSO }\end{array}$ & $\begin{array}{c}5 \\
\text { (adult) }\end{array}$ & $\mathbf{M}$ & 0.8 & 1.4 & $2 \cdot 0$ & $\mathbf{2 \cdot 8}$ & $3 \cdot 2$ & $3 \cdot 2$ & $4 \cdot 2$ & $4 \cdot 4$ & $4 \cdot 8$ & $4 \cdot 8$ & $5 \cdot 0$ & $5 \cdot 0$ & $5 \cdot 0$ & $5 \cdot 0$ & $5 \cdot 0$ & $5 \cdot 0$ \\
\hline None* & $\begin{array}{c}5 \\
\text { (adult) }\end{array}$ & $\mathbf{M}$ & 0.4 & 0.4 & 0.6 & $1 \cdot 2$ & $1 \cdot 2$ & 1.6 & $1 \cdot 8$ & $1 \cdot 8$ & $2 \cdot 2$ & $2 \cdot 4$ & $2 \cdot 8$ & $3 \cdot 0$ & 3.0 & $2 \cdot 8$ & $2 \cdot 6$ & 2.6 \\
\hline Nonet & ${ }^{4}$ & $\mathbf{M}$ & $\mathbf{0}$ & $\mathbf{0}$ & 0 & $\mathbf{0}$ & 0 & $\mathbf{0}$ & $\mathbf{0}$ & $\mathbf{0}$ & 0 & $\mathbf{0}$ & $\mathbf{0}$ & 0 & 0 & 0 & 0 & 0 \\
\hline
\end{tabular}

*In same cage as rats given $2 \times 200 \mathrm{mg} / \mathrm{kg}$ in DMSO

†In separate cage

Figures are mean degrees of disability expressed on a five-point scale 
PERIPHERAL NERVOUS SYSTEM No significant changes were found in anterior horn cells of lumbar or cervical regions of the spinal cords at any time other than a slight increase in glial nuclei (astrocytes) in the surrounding anterior horns in animals kept for one month or more after poisoning (Fig. 1). Dorsal root ganglion cells after 10 days showed minimal alterations in the Nissl pattern in many cells that were of doubtful significance. An occasional mitotic figure was found in satellite cells at 10 days. In animals kept for one month or more after poisoning many of the large cells appeared somewhat smaller than normal, and an occasional chromatolytic cell was seen (Fig. 2); no cell death occurred, and no residual nodules were seen.

In the sciatic nerves, early Wallerian degeneration was evident in many nerve fibres at the 10th day (Figs. 3 and 6), but these were less numerous proximally than distally. No degeneration was seen in ventral or dorsal spinal roots, except for occasional degenerating sensory fibres entering the dorsal horns of the lumbar spinal cord.

Sampling muscles with the sudan black B method showed abundant early fragmentation of nerve fibres that was greater and more extensive in distal muscles below the knee than in proximal muscles. Occasional motor nerve fibres were seen fragmenting in psoas muscles at the 10th day, but the numbers were very few by comparison with tibial and plantar muscles. In muscies from the latter regions, widespread denervation of both motor and sensory fibres was found on the 10th day and was more severe on the 17th day. These findings accord with the increasing functional disturbances during this period and the greater weakness in more distal muscles. All types of sensory fibres appeared to be affected, and denervation of the sensory apparatus

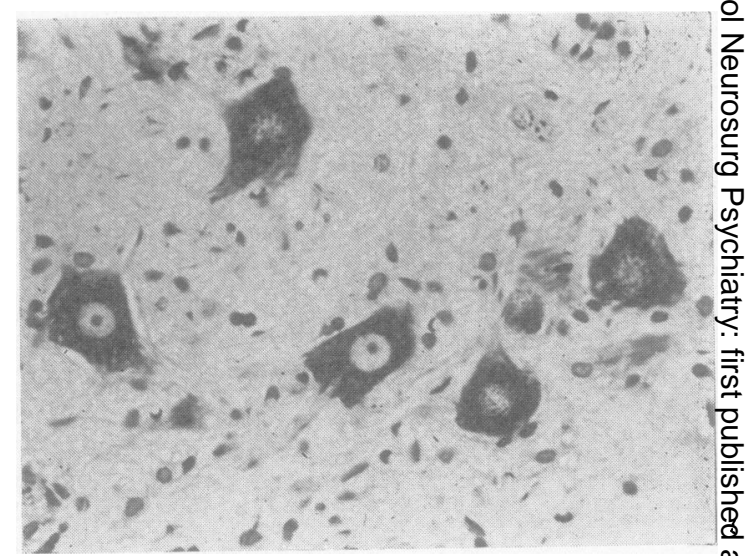

FIG. 1. Anterior horn cells of lumbar cord 14 days after के poisoning. Cresyl fast violet $(\times 195)$.

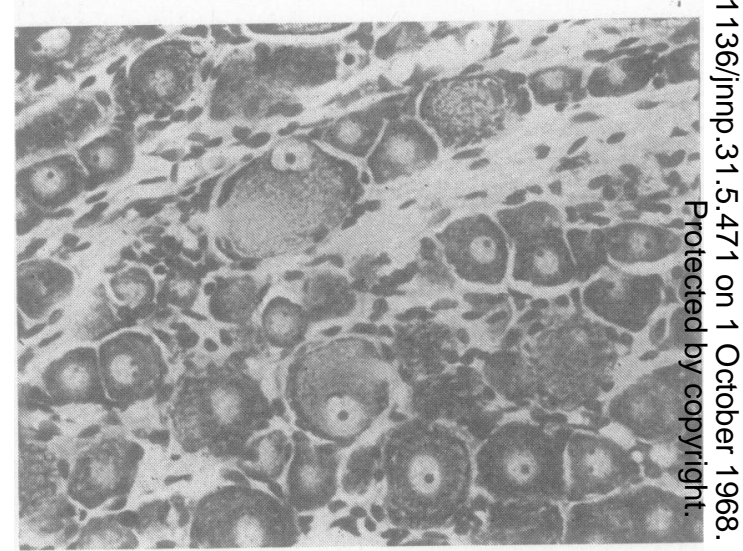

FIG. 2. Lumbar dorsal root ganglion cells 30 days after poisoning showing occasional chromatolytic cell. Cresyl fast violet $(\times 195)$.

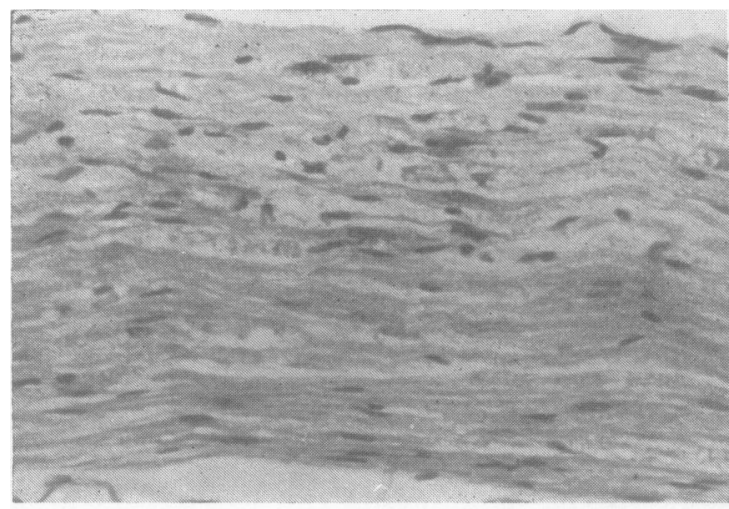

(a)

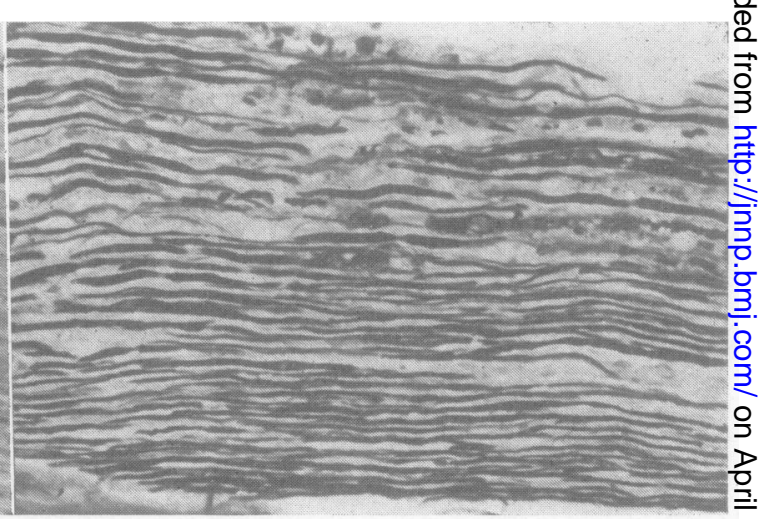

(b)

FIG. 3. Sciatic nerve 14 days after poisoning showing occasional fibre undergoing Wallerian change with increased $\mathrm{N}$ cellularity (a) and fragmentation of axons (b). (a) H.\&. E. (b) Glees \& Marsland ( $\times 195)$. 


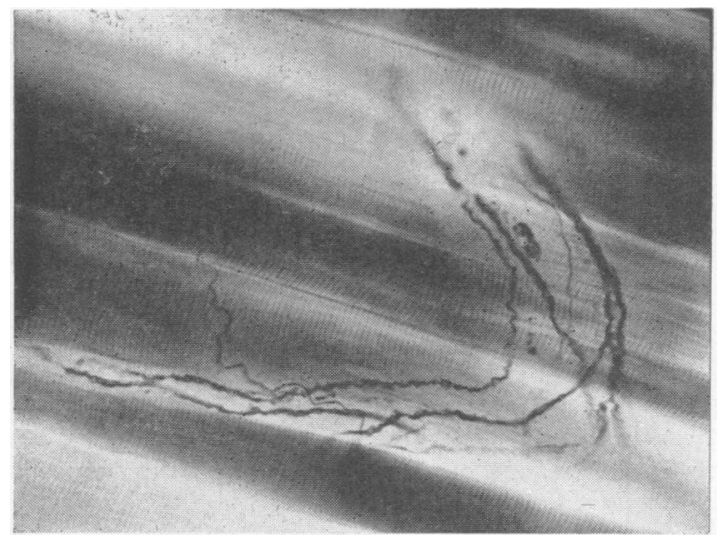

FIG. 4. Quadriceps femoris muscle showing fragmentation of one fibre and fine regenerating fibres. Glees \& Marsland $(\times 195)$.

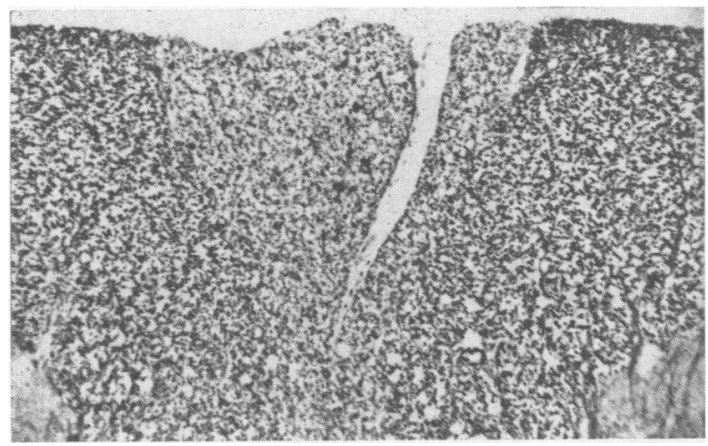

FIG. 5. Dorsal columns in cervical region at 14 th day showing loss of axons and gliosis. Glees \& Marsland $(\times 56)$.

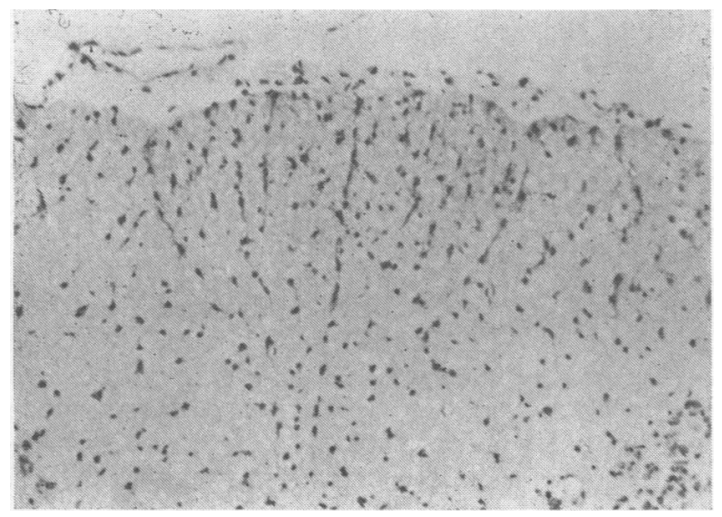

FIG. 6. Dorsal columns as for Fig. 5 showing increase in glial cells. Cresyl fast violet $(\times 82)$. of muscle spindles was as common as changes in Golgi tendon organs. No changes other than later denervation atrophy were seen in muscle fibres. Extensive denervation of cutaneous nerves of the foot and of the snout were found in silver-stained sections of skin from the 10th day onwards.

In muscles, an abundance of collateral and fewer ultraterminal sprouts were found from surviviving fibres from the 10th day in silver stained preparations (Fig. 4).

CENTRAL NERVOUS SYSTEM The most constant finding was severe denervation with microglial and astrocytic response in the dorsal columns (Figs. 5 and 6). This was evident from the 17th day onwards, and was fully developed at the end of one month. The degeneration was most evident in the cervical region, but was also present in the thoracic region, and to a lesser extent in the lumbar region. A few degenerating fibres were occasionally found in lumbar spinal roots, but not in cervical roots.

In addition, occasional clusters of microglia were present in dorsolateral, lateral, and ventral columns in animals killed one month after poisoning with $2 \times 200 \mathrm{mg} / \mathrm{kg}$. These foci suggested that fibres were also degenerating in those pathways as well, and after $2 \times 400 \mathrm{mg} / \mathrm{kg}$ more marked changes occurred in lateral and ventral columns. The spinocerebellar tracts in the medulla, however, did not show marked fibre loss after $2 \times 200 \mathrm{mg} / \mathrm{kg}$. A similar focal increase in glia was also seen in lumbar segments in the motor tract in the dorsal columns at this time. Marchi preparations also showed changes in these tracts (Fig. 7).

No changes in nerve cells or in fibre tracts were found in any other region of the neuraxis by the methods employed.

FIBRE DIAMETER STUDIES The diameters of nerve fibres in the saphenous nerve above the knee and in the posterior tibial nerve above the ankle were determined at 17 and 35 days after poisoning.

At 17 days, the posterior tibial nerves showed a pattern of fibre size similar to normal and only a slight reduction in numbers was found (Fig. 8a). At 35 days, the numbers of fibres had fallen to about half that of normal and there was a proportionate reduction in the larger diameter groups (Figs. 8b and 9).

The saphenous nerves showed no significant change from normal either at 17 or 35 days, despite the occurrence of denervation in the terminals within their territory of innervation. A few degenerating fibres were visible, but since this nerve was sampled above the knee, the fibres were probably too proximal to show marked changes. 


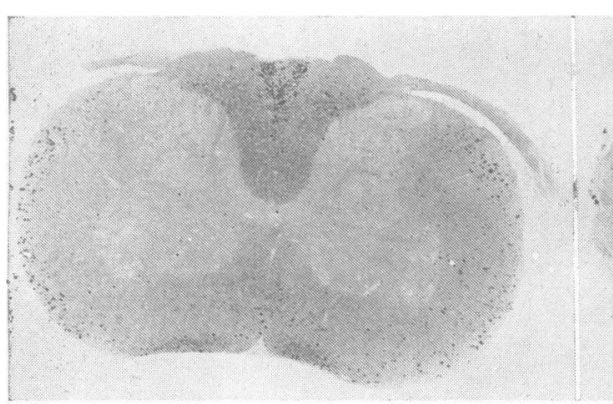

(a) (b)

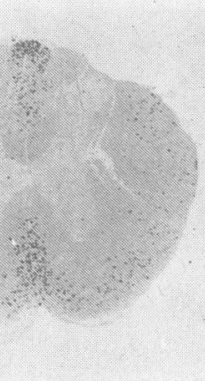

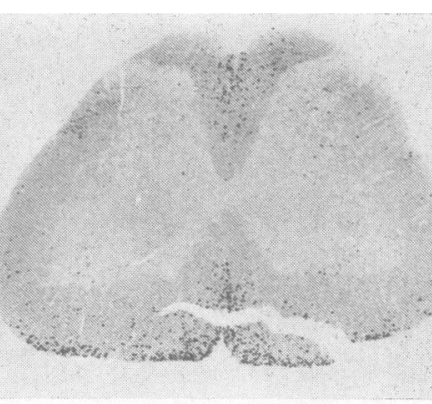

(c)

FIG. 7. Marchi preparations from (a) cervical; (b) thoracic; and (c) lumbar levels of spinal cord showing greater amounts of degeneration in the rostral regions of ascending tracts, and in caudal regions of descending tracts $(\times 16)$.

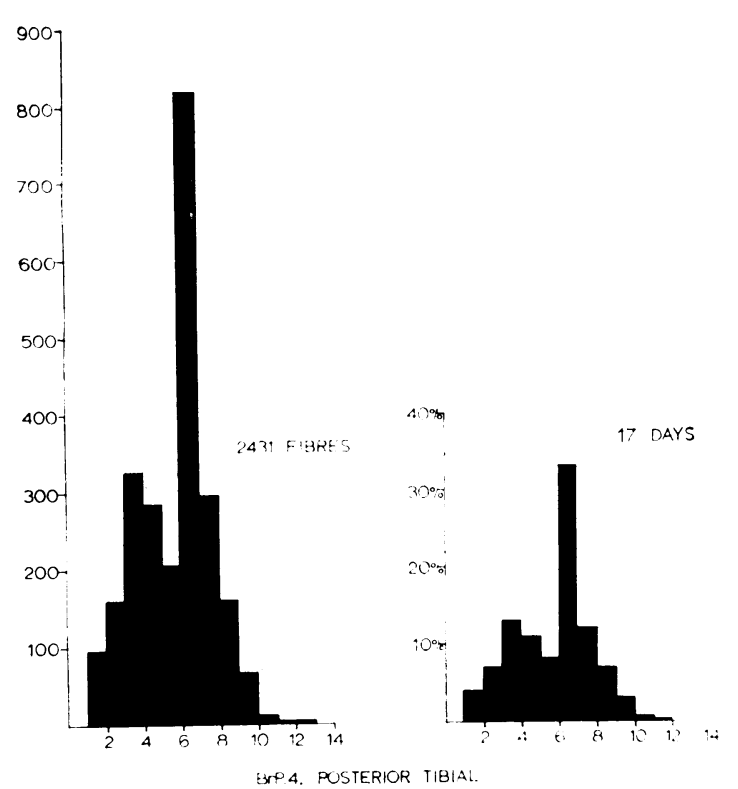

FIG. 8a.

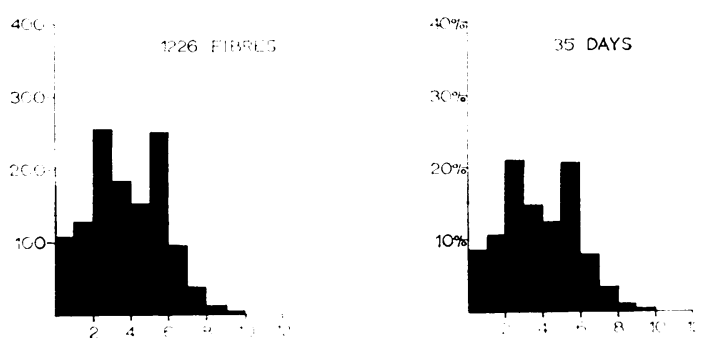

FIG. $8 \mathrm{~b}$.

FIG. 8. Histograms of fibre size distribution in posterior tibial nerves (a) 17, and (b) 35 days after poisoning. On the left the fibre size is set against fibre number, and on the right this is set against percentage of fibres in each class.

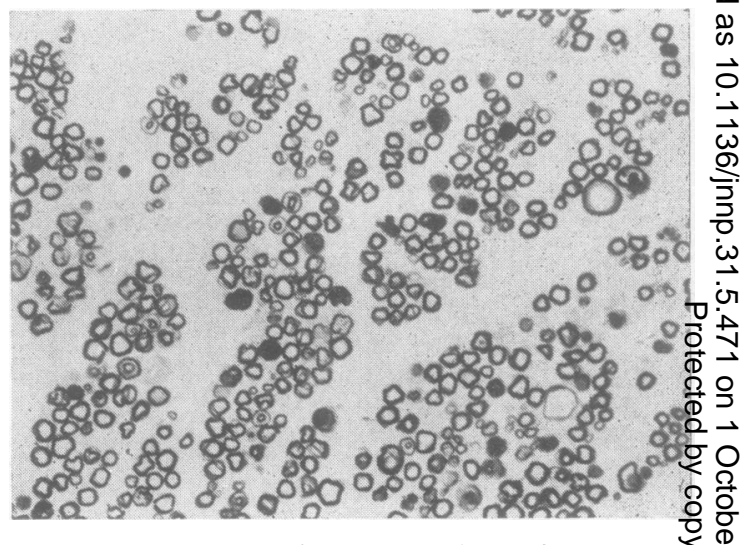

FIG. 9. Posterior tibial nerve 35 days after poisoning. showing many degenerating black masses and a fer swollen fibres undergoing early degeneration. Flemming $\infty$ fixed-Hx $(\times 195)$.

\section{DISCUSSION}

Several points emerged from the results of this $\frac{\mathscr{Q}}{\mathbb{Q}}$ study of the neurotoxic action of p-bromophenyl- $\stackrel{2}{\Rightarrow}$ acetylurea (p-BPAU), and many of these may be profitably compared with the neurotoxic activity of certain organo-phosphorus (O-P) compounds. Most striking is the delay period which is about eight days, both with O-P compounds and p-BPAU. This period can be increased in both instances by reducing the dose and, at the same time, there is a $\frac{\text { O }}{3}$ reduction in the severity of the neurological effects. Increasing the dose of p-BPAU beyond $2 \times 200$ $\mathrm{mg} / \mathrm{kg}$ only very slightly shortened this period, in the same way as occurs with various $O-P$ compounds 을 given in doses above that necessary to cause neuro- $\rightarrow$ toxicity (Cavanagh, Davies, Holland, and Lancaster, 1961).

The second most striking feature is the distal ${ }^{\circ}$ distribution of the earliest changes with p-BPAU. N 
Flaccidity, weakness, and inco-ordination regularly occurred in the hind paws before weakness of more proximal regions, and the fore limbs became involved only after an interval of several days, when the hind paws were already severely affected. This pattern of functional disturbance is quite typical of poisoning in man due to O-cresyl phosphates (Cavanagh, 1964a), and is an accurate reflection of the anatomical spread of the denervation process, firstly from longer to shorter fibres, and secondly from hind to fore limbs. This 'dying back' process has been demonstrated with O-cresyl phosphate compounds in the cat (Cavanagh, 1964b), where it was possible to show that longer and larger diameter nerve fibres were affected earlier than shorter and thinner fibres. This process has not, however, been unequivocally shown in other species-that is, chicken and man-for reasons of technical difficulty, although it is inferred with reasonable certainty. O-P neurotoxicity is difficult to produce in rats (Majno and Karnovsky, 1961) and only after an extensive injection schedule of Mipafox (NN'diamidic-dimethyl-phosphoro-fluoridate). These authors, however, demonstrated quite clearly in this species that the distal regions of the nerves were more extensively affected than proximal regions. Fibre diameter measurements were not done, however; with p-BPAU fibre diameter measurements of the posterior nerves near the ankle show minimal changes at 17 days, when functional disturbances in the foot are maximal, and denervation in foot muscles is severe. By $\mathbf{3 5}$ days, however, there is a distinct reduction in the proportion of larger diameter fibres in this nerve. There is, thus, not only a noteworthy lapse of time between terminal denervation and overt changes in the more proximally lying nerve trunk, but larger diameter fibres appear more likely to be affected. The effect is, admittedly, less clear cut than was found with O-cresyl phosphate in cat, possibly because of the larger range of fibre diameters in the latter species. So far as the general pattern and selectivity of the process is concerned, p-BPAU behaves in the rat as O-P does in other species in tending to cause distal degeneration in long fibres before short ones, and larger diameter fibres more than smaller fibres. In both classes of poison no degenerating fibres can be traced into the spinal roots other than occasional dorsal root fibres in the lumbar region with $\mathrm{p}$ BPAU, and the nerve cell bodies-both motor and sensory-remain substantially unaltered during the whole paralytic process.

Another point of similarity is the reduced susceptibility of immature animals. Young weanling rats developed after a dose of $2 \times 200 \mathrm{mg} / \mathrm{kg}$ p-BPAU a degree of paresis that was equivalent to or slightly less than that found after $2 \times 100 \mathrm{mg} / \mathrm{kg}$ in adult animals. Their recovery was, if anything, more rapid and complete than that seen in adult animals. Similarly reduced sensitivity to O-P compounds has been noted in immature chickens (Dr. J. M. Barnes, personal communication). The significance of these two parallel observations is not clear, but one factor must certainly be the enhanced metabolic activity of the immature, as opposed to the mature neurones, and their greater capacity for regeneration and nerve fibre growth. While the explanation for this phenomenon must rest unclear at the moment, the observations remain relevant to this discussion.

Species sensitivity to these two classes of compound are of interest because of certain apparent reciprocal relationships. While guinea-pigs and rabbits appear from preliminary studies to be insensitive both to O-P compounds (Barnes and Denz, 1953) and to p-BPAU, the species (chicken) that is very sensitive to O-P compounds seems to be insensitive to p-BPAU, and that species known to be very insensitive to O-P compounds (rat) is sensitive to p-BPAU. Nothing definite can be concluded from these observations except that further studies need to be made in other species to determine the veracity and significance of this reciprocal relationship, and that this must be taken into account in any final explanation of the biochemical mechanism underlying these neuropathic processes.

The changes in the spinal pathways are, admittedly, somewhat different from those caused by O-P compounds. In whatever species this has been studied, O-P compounds produce degeneration in the distal regions of the long pathways, so that the spinocerebellar tracts and posterior columns show degeneration in the medullary or upper spinal regions of these ascending (sensory) fibres. The descending (motor) tracts show maximal changes in the lumbosacral spinal regions. This remarkably constant pattern is found in chicken (Barnes and Denz, 1953; Cavanagh, 1954; Fenton, 1955), cat (Cavanagh and Patangia, 1965), and man (Aring, 1942). With p-BPAU in the rat, the posterior columns were very severely affected, especially in cervical regions, and the longer more medial fibres tended to be more affected than the shorter more laterally lying fibres. Involvement of other long pathways was less marked, however, but with the largest dose used $(2 \times 400 \mathrm{mg} / \mathrm{kg})$ many isolated fibres were clearly found degenerating in the lateral, dorsolateral, and ventral regions of the spinal cord, ascending fibres showing changes in cervical regions, and descending fibres in the lumbar regions. The spinal tracts of the rat are small and it may for this 
reason be difficult to identify changes here with the same clarity as they can be seen in the longer pathways of the chicken or the more massive tracts of the cat. Certainly, however, the chief change in the spinal cord caused by p-BPAU was degeneration of the posterior columns and, in this respect, the neurotoxic lesion seems to differ from that of O-P toxicity in other species.

While, thus, there are many similarities between the neurotoxic actions of these two classes of compounds, there are some intriguing dissimilarities as well. Nothing is known of the metabolic activity of p-bromophenylacetylurea and very little about that of the parent substance. This and its analogue phenylethylacetylurea (pheneturide) both have anti-epileptic activity (Everett and Richards, 1952; Swinyard, Brown, and Goodman, 1952; Weaver, Swinyard, and Goodman, 1952), and studies with $C^{14}$ labelled pheneturide (Glasson, Lerch, and Benakis, 1960) have shown that it is stored to some extent in the liver, some being still detectable after 48 hours. Its metabolic action and detoxication route are, however, unknown.

Its very low solubility in aqueous and even in organic solvents is reminiscent of the arylphosphates and might suggest that conversion in a like manner might occur to produce a toxic product (Baron, Bennett, and Casida, 1962). The indications noted here that transfer of toxic material in doses high enough to produce paralysis and spinal tract changes can occur, albeit mild, suggest the possibility of a toxic (and more potent) conversion product being transferred from one animal to another. Nonetheless, despite our present ignorance of the metabolic background to this lesion, it is one that might well be looked upon as a good experimental model for the 'dying back' process in the rat.

\section{SUMMARY}

Certain aspects of the toxicology of, and the anatomical changes caused by, oral doses of p-bromophenylacetylurea have been studied in rats. There is a clear delay period of about eight days, the duration of which is dose-dependent, before the onset of abnormal signs; the paresis affects the hind limbs earlier than the fore limbs, and the distal parts of the limbs earlier and more severely than the proximal. Anatomically, long fibres are damaged more than short fibres and there appears to be greater sensitivity of larger diameter fibres. The process is thus typical of a 'dying back' process and $\frac{\text { O }}{Z}$ is closely analogous to the neurotoxic lesion caused $\mathbb{Q}$ by O-P compounds. In the spinal cord the major lesion is degeneration of the posterior columns, but $\stackrel{\text { S }}{\subseteq}$ minor changes also occur distally in other longe tracts. Nerve cell bodies do not show significant 0 changes.

Our thanks are due to Dr. J. M. Barnes of the M.R.C. Toxicology Research Unit, Carshalton, for introducing : us to this substance and for giving us advice on its use. We also wish to thank Miss Christine Botwright and Miss Susan Batty for the careful histological preparations, $\frac{C}{\sigma}$ and Mr. J. A. Mills for the photographs in Figure 7.

\section{REFERENCES}

Aring, C. D. (1942). The systemic nervous affinity of triorthocresyl phosphate (Jamaica Ginger Palsy). Brain, 65, 34-47.

Barnes, J. M., and Denz, F. A. (1953). Experimental demyelination ${ }^{-}$ with organophosphorus compounds. J. Path. Bact., 65, 597-605. $\overrightarrow{\mid \vec{c}}$

Baron, R. L., Bennett, D. R., and Casida, J. E. (1962). Neurotoxic syndrome produced in chickens by a cyclic phosphate metabolite of tri-o-cresyl phosphate-a clinical and pathological study. Brit. J. Pharmacol., 18, 465-474.

Cavanagh, J. B. (1954). The toxic effects of tri-ortho-cresyl phosphate $\omega$ on the nervous system. An experimental study in hens. $J . \rightarrow$ Neurol. Neurosurg. Psychiat., 17, 163-172.

_ (1964a). The significance of the 'dying back' process in exper mental and human neurological disease. Int. Rev. exp. PaP. 3, 219-267.

- (1964b). Peripheral nerve changes in ortho-cresyl phosph艇 poisoning in the cat. J. Path. Bact., 87, 365-383.

- (1967). On the pattern change in peripheral nerves produced by isoniazid intoxication in rats. J. Neurol. Neurosurg. Psychiox, 30, 26-33.

—, Davies, D. R., Holland, P., and Lancaster, M. (1961). Cof - 응 parison of the functional effects of Dyflos, Tri-o-cresyl phes- 믄 phate and Tri-p-ethyl phenyl phosphate in chickens. Brit $\overrightarrow{2}$ : Pharmacol., 17, 21-27.

- and Patangia, G. N. (1965). Changes in the central nervoưs system in the cat as the result of tri-o-cresyl phosphate poison-. ing. Brain, 88, 165-180.

Diezel, P. B., and Quadbeck, G. (1960). Nervenschädigung durch p-Bromphenylacetyl-Harnstoff. Naunyn-Schmiedeberg's Arch. exp. Path. Pharmak., 238, 534-541.

Everett, G. M., and Richards, R. K. (1952). Pharmacological studies of Phenylacetylurea (phenurone). An anticonvulsant drug. $\frac{\mathrm{O}}{\mathrm{D}}$ J. Pharmacol. exp. Ther., 106, 303-313.

Fenton, J. C. B. (1955). The nature of the paralysis in chickens following organo-phosphorus poisoning. J. Path. Bact., 69, 윽 181-189.

Glasson, B., Lerch, P., and Benakis, A. (1960). Repartition et élimination du Phénêturide marqué. Therapie, 15, 368-376.

Majno, G., and Karnovsky, M. L. (1961). A biochemical and mor- phological study of myelination and demyelination. III. Effect $\bar{Z}$ of an organo-phosphorus compound (Mipafox) on the bio-? synthesis of lipid by nervous tissue of rats and hens. $J$. Neuro-. chem., 8, 1-16.

Swinyard, E. A., Brown, w. C., and Goodman, L. S. (1952). Com-3 parative assays of antiepileptic drugs in mice and rats. $J$. Pharmacol. exp. Ther., 106, 319-330.

Weaver, L. C., Swinyard, E. A. and Goodman, L. S. (1952). Effects of liver injury and nephrectomy on anti-convulsant activity of $O$ phenacemide. Proc. Soc. exp. Biol. (N.Y.), 80, 744-746. 